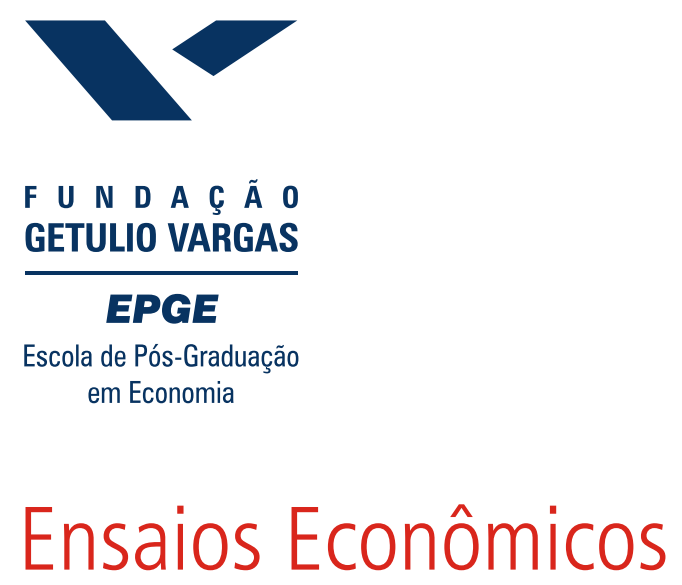

$$
\begin{aligned}
& \text { Escola de } \\
& \text { Pós Graduação } \\
& \text { em Economia } \\
& \text { da Fundação } \\
& \text { Getulio Vargas }
\end{aligned}
$$

Are price limits on futures markets that cool? Evidence from the Brazilian Mercantile and Futures Exchange

Marcelo Fernandes, Marco Aurélio dos Santos Rocha 
Os artigos publicados são de inteira responsabilidade de seus autores. As opiniões neles emitidas não exprimem, necessariamente, o ponto de vista da Fundação Getulio Vargas. 


\title{
Are price limits on futures markets that cool? Evidence from the Brazilian Mercantile and Futures Exchange
}

\author{
Marcelo Fernandes \\ Queen Mary, University of London \\ Mile End, London, E1 4NS, UK \\ Tel: +442078825082 \\ E-mail: m.fernandes@qmul.ac.uk
}

\author{
Marco Aurélio dos Santos Rocha \\ University of Illinois at Urbana-Champaign \\ E-mail: mdrocha2@uiuc.edu
}

\begin{abstract}
This paper investigates the impact of price limits on the Brazilian futures markets using high frequency data. The aim is to identify whether there is a cool-off or a magnet effect. For that purpose, we examine a tick-by-tick data set that includes all contracts on the São Paulo stock index futures traded on the Brazilian Mercantile and Futures Exchange from January 1997 to December 1999. The results indicate that the conditional mean features a floor cool-off effect, whereas the conditional variance significantly increases as the price approaches the upper limit. We then build a trading strategy that accounts for the cool-off effect in the conditional mean so as to demonstrate that the latter has not only statistical, but also economic significance. The in-sample Sharpe ratio indeed is way superior to the buy-and-hold benchmarks we consider, whereas out-of-sample results evince similar performances.
\end{abstract}

JEL Classification: C22, G12, G15, G18.

Keywords: cool-off effect, futures markets, magnet effect, price limits, transactions data.

Acknowledgements: We are grateful to Verdi Rosa and Cicero Vieira at BM\&F for providing the data as well as for helpful discussions. We are also indebted to two anonymous referees, Marco Bonomo, Walter Novaes, and seminar participants at ECARES, Université Libre de Bruxelles; Universidade Nova de Lisboa; Warwick Business School; Queen Mary, University of London; International Conference on Finance in Copenhagen, and EC "Econometrics of Financial and Insurance Risk" in Istanbul for their valuable comments and suggestions. The authors thank the financial support from the CNPq and from the Central Bank of Brazil, respectively. The usual disclaimer applies. 


\section{Introduction}

Price limits are market mechanisms that aim to restrain extreme oscillation in prices. Exchange markets operating under such rules set the allowable price fluctuation either to each traded security or to the whole market. Although no negotiation may take place outside the price limits (i.e., price censorship), the market does not halt as in circuit breakers. Of particular interest is the imposition of price limits rules on futures markets given that they may serve as partial substitutes for margin requirements in ensuring contract performance without resorting to costly litigations (Brennan, 1986; Kodres and O'Brien, 1994; Chowdry and Nanda, 1998). Furthermore, besides preventing large price movements, price limits restrict the daily liability of market participants and grant investors time to reassess the fundamental value of the securities after a limit hit. Also, similar to the honeymoon effect of a credible exchange-rate target zone (Krugman, 1991), daily price limits may induce mean reversion in the returns data, giving way to the so-called cool-off effect.

In spite of their benefits, price limits may affect trading activity and hence involve some potential costs. Fama (1989) questions whether price limits constrain imbalance corrections toward the fundamental value. Even though price limits prevent large one-day price changes, prices presumably continue to move toward their equilibria. Price limits would therefore serve no purpose other than to delay price discovery. Lehmann (1989) suggests that price limits may cause the volatility to increase on the subsequent trading days, since immediate equilibrium price realization may not occur. Lehmann also argues that the trading volume increases on the days following a limit hit, supporting that price limits interfere with trades.

Subrahmanyam (1994) investigates the effect of impediments to trade on the ex-ante trading decision of market participants. His theoretical results suggest that the price variability and the probability of hitting the limits increase as prices approach the limits. This is consistent with another detrimental hypothesis, namely, the magnet effect, which implies that prices accelerate toward the limits, as they get closer to them. As long as the model predicts an increase in the price variability, it gives rise to the magnet effect. Subrahmanyam further shows that, if there are alternative trading venues, the trading volume and volatility increase in 'satellite' markets, whereas decrease in the dominant market. 
Price limits thus entail potential benefits as well as potential harming effects on futures markets. They may end up as either a calming or a destabilizing factor on the price formation process depending on whether the cool-off or the magnet effect dominates. This debate also dominates the empirical literature on price limits. Yet, the available empirical results do not give a definite answer to whether price limits calm or heat up the market. Kim and Rhee (1997) find evidence against the efficacy of price limits in the Tokyo stock exchange. They evince that the volatility of stocks reaching the limits does not revert to normal levels as quickly as the stocks that almost (but do not) reach the limits. Also, they observe price continuations occurring more frequently and increasing trading activity on the day after limit hits. Arak and Cook (1997) study the calming or attracting role of the price limits using US Treasury bond futures prices. They use the returns of the first half hour of the days subsequent to great overnight news. Their results suggest that the limits, not the news, are the cause of price reversals. Despite the small magnitude of their coefficient estimates, the findings are consistent with a cool-off rather than a magnet effect.

The most recent studies attempt to refine the measurement of such effects by working with high frequency rather than daily data. Cho, Russell, Tiao and Tsay (2003) and Kim and Yang (2003) investigate the effects of price limits on the Taiwan stock exchange. Cho et al. model the intraday returns using an ARMA-GARCH process with dummy variables that attempt to capture the magnet effect. Their results suggest that the magnet effect is both statistically and economically significant. In contrast, Kim and Yang evince that the price limits induce overreaction when prices approach the limits, though there is a calming effect once prices hit a limit. Berkman and Steenbeek (1998) use Nikkei futures transaction data, from two distinct exchanges, to evaluate Subrahmanyam's (1994) hypotheses. Although they find no relation between the distance from previous' day closing price and the stock index futures return, they argue that the contemporaneous link between the two markets may mitigate the effect of price limits. They however find evidence supporting Subrahmanyam's hypothesis about the interaction between the dominant and satellite markets.

The main goal of this paper is to investigate the ex-ante effects of daily price limits on futures markets, that is to say, how they influence the price formation process before coming into action. We contribute to the literature by modeling high frequency data to evaluate whether price limits 
entail a cool-off or magnet effect. We have a unique data set from the Brazilian Mercantile and Futures Exchange (BM\&F) that includes intraday data on São Paulo stock exchange index futures (IBOVESPA futures), ranging from January 1997 to December 1999.

Our database is very convenient to test the cool-off effect versus the magnet effect on the ex-ante trading decisions of the market participants because there are very few limit hits despite of the nonnegligible number of observations in vicinity of the limits. A data set with a high frequency of limit hits is paramount only to identify ex-post rather than ex-ante effects. Besides, limit hits imply a form of censoring in the price process. Although Cho et al. (2003) recognize that "once the price reaches the limits, it can stay at the limits or move only in one direction" (page 139), they avoid discussing censoring and simply exclude the observations at the limits. Such a procedure entails inconsistent estimates unless the censoring relation is strictly exogenous to the price formation process. See, for example, Dhrymes (1986) for a discussion on truncated dependent variables as well as Bekaert and Gray (1998) for a similar empirical issue within a different context. However, strict exogeneity is not a reasonable assumption given that price limits affect the ex-ante trading decisions of the market participants (Subrahmanyam, 1994).

The extremely low frequency of limit hits in our data set ensures that censoring is not an issue and hence one may consistently estimate the stochastic process governing the dynamics of the IBOVESPA futures price. Moreover, the fact that we have access to high frequency data is key given that daily data fail to detect the impact of price limits on BM\&F contracts. The use of high frequency data allows us to evaluate significant changes in the conditional mean and variance that occur during a trading day and to correctly appreciate the ex-ante effects of price limits. As in Cho et al. (2003), we build an econometric model to test the cool-off against the magnet effect both in the conditional mean and variance.

Our findings suggest that the price limits at BM\&F help calming down the market when prices approach the floor. The upper limit affects prices only through the conditional variance. In particular, volatility increases as prices approach the ceiling. We argue nonetheless that the overall impact is consistent with a stronger floor cool-off effect. As in Cho et al. (2003), we complement our econometric analysis by examining the economic relevance of the price limits effects. We show that a trading strategy that accounts for the floor cool-off effect in the conditional mean outper- 
forms the usual buy-and-hold strategy for the Brazilian stock market futures and spot indexes. The in-sample Sharpe ratio of our trading strategy indeed is way superior to the Sharpe ratios of the buy-and-hold benchmarks, whereas out-of-sample results evince similar performances.

The remainder of this study is organized as follows. Section 2 outlines the main trading of the BM\&F and then describes the IBOVESPA futures contract and the data. Section 3 defines the econometric model and then discusses the implications of our empirical results. As well, we argue that our findings are quite robust in the sense that different data samples and model specifications yield the same qualitative results. Section 4 evaluates the economic relevance of the price limits effects. Section 5 offers some concluding remarks.

\section{The Brazilian Mercantile and Futures Exchange}

$\mathrm{BM} \& \mathrm{~F}$ is a private association that organizes, regulates and supervises futures markets in Brazil. Futures and forward contracts, options on actuals, options on futures, swaps and structured transactions trade on BM\&F. It works through a clearing system that assumes responsibility for the settlement of all trades. There are three clearinghouses that render trade registration, clearing and settlement services according to the features of each market. The derivatives clearinghouse deals with derivatives on gold, stock indexes, exchange rates, interest rates, sovereign debt, swaps, and agricultural commodities. The foreign exchange clearinghouse has a system for the settlement of international transactions in foreign currency that avoids that, after paying local currency to another player, a bank does not receive the foreign currency, or vice-versa. The securities clearinghouse provides services relating to the market of government bonds and fixed-income securities issued by financial institutions.

The BM\&F derivatives clearinghouse registers almost 30 million contracts on São Paulo stock exchange index (IBOVESPA) futures, with a traded volume adding up to US\$ 13 billion, over the period running from January 1997 to December 1999. The quotes are on stock index points times the Brazilian Real $(\mathrm{R} \$)$ value of each point. ${ }^{1}$ The expiration dates of the IBOVESPA futures contracts are on the Wednesday closest to the 15th calendar day of every even-numbered month (or the next business day, if it is a holiday). Trading is continuous from 10:00 to 13:00 and from

\footnotetext{
1 The current value of each point is $\mathrm{R} \$ 3$. The complete description of the IBOVESPA futures contract is available at http://www.bmf.com.br/2004/pages/frame.asp?idioma=2\&area=contratos\&link_char=Index1.
} 
14:00 to 17:00 unless there is a price limit hit or the São Paulo stock exchange suspends trading on the spot market. If a suspension occurs on the spot market, trading on the futures market halt for the same length of time.

The minimum price variation is 5 points, whereas price limits are relative to the previous day's settlement price of the nearest contract. There is a hit at the ceiling on day $d$ if there is at least one time interval, say $\tau$, on day $d$ for which $P_{\tau, d}=S_{d-1}\left(1+O_{d}\right)$, where $P_{\tau, d}$ denotes the price observed at the time interval $\tau$ on day $d, S_{d-1}$ is the previous day's settlement price, and $O_{d}$ is the maximum percentage oscillation on day $d$. Similarly, there is a hit at the floor if $P_{\tau, d}=S_{d-1}\left(1-O_{d}\right)$ for at least one time interval $\tau$ on day $d$.

There are no price limits for contracts on their last three days of trading. Table 1 documents that the price limits vary considerably across time at BM\&F. In fact, there were no price limits before November 1997, whereas there has been no change in the $10 \%$ daily maximum percentage oscillation since August 1999. In response to the Brazilian currency devaluation following the change in the exchange rate regime, $\mathrm{BM} \& \mathrm{~F}$ has raised the daily maximum percentage oscillation from $15 \%$ to $25 \%$ for only one day, viz. January 18,1999 . The variation in the price limits provide a suitable context to test for the ex-ante effects of price limits.

\subsection{Data Description}

Our database combines two distinct data sets provided by BM\&F. The first contains data for every IBOVESPA futures transaction, including information about the commodity type, date and time of trade, expiration date, contract value, and number of contracts. The second data set consists of daily maximum, minimum, and settlement prices for every contract. We use the latter to determine the daily price limits over our sample period, which ranges from January 1997 to December 1999. Our sample covers several distressing periods in the Brazilian financial market: e.g., the Asian and Russian crises, the restructuring of the Brazilian banking sector, the presidential election, and the change in Brazilian exchange rate regime. It therefore is surprising that prices seldom hit the limits. Table 2 indeed reports that the relative frequency of daily limit hits is about $1 \%$ and, even more surprisingly, that most limit hits are at the ceiling rather than at the floor.

We consider only trading days, and so our sample excludes holidays and weekends. To form return series for the IBOVESPA futures contract, we account for two features of IBOVESPA futures 
data. First, we pay special attention to liquidity given that liquid contracts convey much more information than illiquid contracts. It turns out that the close-to-maturity futures contracts are always the most liquid. The volume of the next-maturing contract typically exceeds the volume of the due contract at $\mathrm{BM} \& \mathrm{~F}$ only on the last trading day of the latter, i.e., the day before its expiration (see Figure 1). Second, the contracts result in short time series that end on the due date. We thus carefully combine contracts with different maturities and expiration dates so as to form a single time series for the IBOVESPA futures price (see Martens, 2002; Martens and Zein, 2004). More precisely, we track the contract with the nearest expiration date and then switch to the next-maturing contract one day before the expiration of the former.

As for the dissimilar maturities, we attempt to mitigate cost-of-carry effects by continuously compounding the returns of the IBOVESPA futures. The motivation is that, if the IBOVESPA futures contracts satisfy the forward contracts cost-of-carry model, then there are no cost-of-carry terms in the log-return series. This assumption holds only if marking to market does not have a significant effect in the IBOVESPA futures market, which boils down to assuming no contemporaneous correlation between the spot IBOVESPA price and interest rates. To sum up, consider the following example. Suppose the IBOVESPA April contract expires on Wednesday, April 14. We therefore consider the April futures prices up to the market closure at 17:00 on Tuesday, April 13, and then move to the June futures prices. The last return on April 13 then refers to the log-ratio of the two last observations of the April futures prices, whereas the first return on April 14 corresponds to the log-ratio of the first observation on Wednesday and the last observation on Tuesday of the June futures price.

The BM\&F database comprises tick-by-tick data, hence the series we have so far for the IBOVESPA futures returns is irregularly spaced in time. To avoid using nonstandard time-series techniques (see Grammig and Wellner, 2002), we filter the observations at regular time intervals of 5, 10, 15, 20, and 30 minutes. For example, at a frequency of 20 minutes, the return at 11:20 equals the log-ratio between the last price before 11:20 and the last price before 11:00. If there are no observations since 11:00, then we input a zero return at 11:20. To select the level of time aggregation, we compute the number of zero-returns we observe at each frequency so as to account for the risk of spurious autocorrelation. Figure 2 compares the plot and autocorrelogram of the 
log-return series at the frequencies of 10 and 20 minutes. The palpable difference between the first-order autocorrelations illustrate the spurious autocorrelation pattern that arises due to the larger number of zero-return observations at the frequency of 10 minutes (see also Table 3). In what follows, we focus on data at the frequency of 20 minutes for which there are less than $2.5 \%$ of zero returns.

It is well known that intraday volatility may exhibit a diurnal component in view that trading activity is usually higher in the opening and closure of the market. Figure 3 depicts the time-of-day effect in the volatility as measured by the sample standard deviation of the returns over each 20 minutes interval. As the market closes from 13:00 to 14:00, the volatility actually does not seem to vary much along the day. We nonetheless account for time-of-day effects by considering, as in Cho et al. (2003), diurnally adjusted returns $\tilde{r}_{\tau, d}=r_{\tau, d} / s_{\tau}$, where $r_{\tau, d}$ denotes the log-return at time $\tau$ on day $d$ and $s_{\tau}$ is the sample standard deviation of returns at time $\tau$.

We exclude all overnight returns as well as the few returns at the price limits. The returns from 10:00 to 10:20 (i.e., $\tau=10: 20$ ) basically refer to the overnight return and therefore may behave differently from other intraday returns. Figure 3 indeed shows that they are relatively much more volatile. Similarly, the returns at the price limits are characterized by censoring in the sense that they are bounded to be nonpositive. Fortunately, in contrast to the previous empirical investigations in the literature, our sample has very few limit hits and hence we are confident that censoring will not drive our results. We then stack the resulting intraday observations $\left(\tilde{r}_{10: 40, d}, \ldots, \tilde{r}_{17: 00, d}\right)$ over every trading day $d$ from January 1997 to December 1999, giving way to a unique time series $r_{t}$ with 14,103 observations of the IBOVESPA futures standardized returns.

Figure 2 displays the series of the IBOVESPA futures standardized returns at both the 10 and 20 minutes frequencies as well as their respective autocorrelograms. Although the time series plots feature similar characteristics, the sample autocorrelation functions evince a much higher negative serial correlation of first order at the 10 minutes frequency. It is important to stress that mean reversion does not necessarily imply either an AR or MA structure for two reasons. First, zero returns due to nontrading may engender spurious negative autocorrelation of first order (Lo and MacKinlay, 1990), which (at least, partially) explains why the mean reversion is more pronounced at the 10 minutes frequency. Second, a cool-off effect in the conditional mean would also entail 
mean reversion analogously to the honeymoon effect of target zones (see, among others, Iannizzotto and Taylor, 1999). The empirical results in Section 3.1 actually document that the cool-off effect indeed is the main responsible for the negative first-order autocorrelation in the IBOVESPA futures returns.

Although the empirical results in Section 3.1 refer to the above series of IBOVESPA futures returns, the sensitivity analysis in Section 3.2 evince that our results are not an artifact due to the way we construct the data. In particular, the qualitative results are very robust to changes in the migration date and sampling frequency. As well, the time-of-day adjustment is innocuous in the sense that working with nonstandardized returns yields very similar results.

\section{Are the daily price limits effects statistically significant?}

In this section, we perform an econometric examination of whether daily price limits at the BM\&F affect the dynamics of the IBOVESPA futures returns. The analysis is purely statistical, though we also investigate the economic relevance of price limits in Section 4. In what follows, we describe the econometric model and then discuss the estimation and testing results. We conclude with a robust analysis that shows that our findings are robust to distinct data samples and model specifications.

As is apparent in Table 3, the series of IBOVESPA futures (standardized) returns displays negative first-order autocorrelation as well as volatility clustering. We therefore model both the conditional mean and variance of the IBOVESPA futures returns using an ARMA-EGARCH framework. In fact, our approach is very similar to the modeling strategy of Cho et al. (2003). There are two differences, however. First, we consider an EGARCH (rather than a GARCH) specification for the conditional variance. This ensures the positivity of the conditional variance without requiring any nonnegativeness constraint in the parameter vector. Second, we consider proximity-to-limit variables, as opposed to Cho et al.'s (2003) dummy variable approach, to evaluate the ex-ante effects of price limits. ${ }^{2}$ In particular, we gauge the distance to the limits by normalizing the differences between the ceiling and the actual price $\left(C_{t}-P_{t}\right)$ and between the actual price and the floor $\left(P_{t}-F_{t}\right)$ by the admissible range $\left(C_{t}-F_{t}\right)$ at time $t .{ }^{3}$ To accommodate the period prior to

\footnotetext{
2 The continuity of the proximity-to-limit variables ensures that we use all observations to identify the ex-ante effects of the daily price limits, resulting in more precise estimates. Engle and Gau (1997) employ a similar strategy to model the conditional volatility of exchange rates under a target zone.

3 To avoid heavy notation, we refer to a single time index $t$ despite the fact that both the ceiling and floor prices are constant over any given day.
} 
the adoption of price limits, we also consider a dummy variable $\delta_{t}$ that takes value one if there are price limits, zero otherwise. The resulting proximity-to-the-limit variables then are $U_{t}=\delta_{t} \frac{C_{t}-F_{t}}{C_{t}-P_{t}}$ and $L_{t}=\delta_{t} \frac{C_{t}-F_{t}}{P_{t}-F_{t}}$.

We employ an AR(1)-EGARCH(1,1) specification so as to account for the first-order autoregressive nature of the conditional mean and variance. To evaluate whether the price limits attract or push back prices as they approach the ceiling and floor prices, we also include the proximity-to-limit variables $U_{t}$ and $L_{t}$ in the conditional mean and variance equations. This gives way to

$$
\begin{aligned}
& r_{t}=\alpha_{0}+\alpha_{1} r_{t-1}+\gamma_{1} U_{t-1}+\gamma_{2} L_{t-1}+\exp \left(\frac{1}{2} h_{t}\right) \epsilon_{t} \\
& h_{t}=\phi_{0}+\phi_{1} h_{t-1}+\theta_{1}\left(\left|\epsilon_{t-1}\right|-\theta_{2} \epsilon_{t-1}\right)+\gamma_{3} U_{t-1}+\gamma_{4} L_{t-1}
\end{aligned}
$$

where $\epsilon_{t}$ forms an iid sequence with mean zero and variance one. The parameter $\phi_{1}$ measure the volatility persistence, whereas $\theta_{2}$ convey information about an eventual leverage effect in the volatility process.

The vector of the proximity-to-limit coefficients $\gamma=\left(\gamma_{1}, \gamma_{2}, \gamma_{3}, \gamma_{4}\right)$ summarizes the ex-ante effects of the price limits in the conditional mean and variance of the IBOVESPA futures returns. If one ignores the repercussion of the price limits in the conditional variance, the magnet effect would dominates either if $\gamma_{1}>0$ and $\gamma_{2} \leq 0$ or if $\gamma_{1} \geq 0$ and $\gamma_{2}<0$, whereas the cool-off effect would prevail either if $\gamma_{1}<0$ and $\gamma_{2} \geq 0$ or if $\gamma_{1} \leq 0$ and $\gamma_{2}>0$. However, it is not so straightforward to identify the magnet and cool-off effects once one takes into account the influence of price limits on the volatility. It is evident that it does not suffice to consider only the conditional mean and variance. One must check whether the likelihood of a limit hit increases or decreases when the price approaches the limit. Put differently, if differentiating the probability of hitting a limit with respect to the corresponding proximity-to-limit variable results in a negative (positive) quantity, then the evidence favors the cool-off (magnet, respectively) effect.

For instance, the conditional probability of reaching the ceiling given the available information set $\Omega_{t-1}$ is

$$
\begin{aligned}
\operatorname{Prob}\left(P_{t} \geq C_{t} \mid \Omega_{t-1}\right) & =\operatorname{Prob}\left(r_{t} \geq \log C_{t}-\log P_{t-1} \mid \Omega_{t-1}\right) \\
& =1-F\left(\frac{\log \frac{C_{t}}{P_{t-1}}-\alpha_{0}-\alpha_{1} r_{t-1}-\gamma_{1} U_{t-1}-\gamma_{2} L_{t-1}}{\exp \left(\frac{\phi_{0}}{2}+\frac{\phi_{1}}{2} h_{t-1}+\frac{\theta_{1}}{2}\left(\left|\epsilon_{t-1}\right|-\theta_{2} \epsilon_{t-1}\right)+\frac{\gamma_{3}}{2} U_{t-1}+\frac{\gamma_{4}}{2} L_{t-1}\right)}\right)
\end{aligned}
$$


where $F$ denotes the cumulative distribution function of the error term $\epsilon_{t}$ in (1). It is straightforward to show that, irrespective of the cumulative distribution function $F$, the first derivative of (3) with respect to the proximity-to-limit variable $U_{t-1}$ will have the same sign of

$\gamma_{1}+\frac{\gamma_{3}}{2}\left(\log C_{t}-\log P_{t-1}-\alpha_{0}-\alpha_{1} r_{t-1}-\gamma_{1} U_{t-1}-\gamma_{2} L_{t-1}\right)$

The magnet effect dominates when the above quantity is positive, whereas the cool-off effect prevails in the event of a negative sign. As for the proximity to the floor price, a similar results follows by substituting $\left(\gamma_{2}, \gamma_{4}\right)$ for $\left(\gamma_{1}, \gamma_{3}\right)$ in the first two terms of $(4)$.

\subsection{Estimation results}

We estimate by quasi-maximum likelihood the augmented $\mathrm{AR}(1)-\mathrm{EGARCH}(1,1)$ model defined by Equations (1) and (2) for the series of IBOVESPA futures returns. The results we report in Table 4 indicate that the first-order autoregressive structures of the conditional mean and variance easily cope with the serial correlation and volatility clustering that characterize the IBOVESPA futures returns. In fact, the estimation and testing results make evident that the autoregressive component in the conditional mean is not really necessary at the 20 minutes frequency, though the next section shows that it is quite significant at higher frequencies due mainly to the increased number of zero returns. This means that the mean reversion that we report in Table 3 at the 20 minutes frequency presumably stems from the cool-off effect of daily price limits.

Before examining the parameter estimates, we check whether our model is congruent so as to ensure that we may indeed conduct statistical inference. The results of Wooldridge's (1991) heteroskedasticity-robust diagnostic tests suggest no evidence of remaining autocorrelation up to the 12 th order in the conditional mean and variance. As our specification seems to deliver a congruent model, we proceed with the analysis of the parameter estimates. The IBOVESPA futures returns display a quite persistent dynamics in the volatility, though we find no evidence of leverage effect. Actually the absence of leverage effect is recurrent in that, for every specification and IBOVESPA returns data we use, the estimate $\hat{\theta}_{2}$ of the leverage parameter is not statistically different from zero.

As for the proximity-to-limit coefficients, the results are very interesting in that we uncover opposing price limit effects in the conditional mean and variance. Although we argue in the last 
section that it is not immediate to evaluate whether price limits entail a magnet or a cool-off effect, the estimates for the proximity-to-limit coefficients imply that the upper and lower limits entail quite distinct effects. In particular, $\hat{\gamma}_{1}$ and $\hat{\gamma}_{4}$ are not statistically different from zero, whereas $\hat{\gamma}_{2}$ and $\hat{\gamma}_{3}$ are both positive. The lower limit thus leads to a cool-off effect in the conditional mean as opposed to the upper limit, which acts only on the volatility. This last piece of evidence chiefly favors the magnet effect hypothesis given that the quantity within parenthesis in (4) is more likely to be positive (and small). The magnet effect is quite weak due to the small magnitude of $\hat{\gamma}_{3}$. Altogether, our findings conform with the data features. The low relative frequency of limit hits warrants a stronger cool-off effect, whereas the magnet effect in the volatility is consistent with the fact that most limit hits are at the ceiling.

\subsection{Robustness analysis}

We revisit our empirical findings so as to evaluate their sensitiveness to the manner we construct the data as well as to the specification of the econometric model. The robustness analysis consists of five steps. First, we test whether there are any qualitative changes in the results owing to variations in the sample period. We consider two subsamples: January 1997 to October 1998 and January 1997 to April 1999. The idea is to check whether the results are driven by the period not subject to the price limits. As we enlarge the time span, the relative number of observations without price limits decreases. Table 4 shows that our statistical model remains congruent for every subsample and that the proximity-to-limit parameters are reasonably stable over time. Further, the ceiling magnet effect and the floor cool-off effect remain statistically significant, and hence our findings are not an artifact due to the sample period.

Second, we observe what happens if we use different migration dates to form the time series for the IBOVESPA futures returns. In particular, we consider switching to the next-maturing contract $m$ days before the expiration of the due contract, where $m$ varies from two to five days. Table 5 documents that there are no significant changes in the results. The sole difference rests on the statistical significance of the negative autoregressive coefficient in the conditional mean. It stems from the fact that the number of zero returns increases as one starts tracking the next-maturing contract before its volume exceeds the volume of the due contract. Notwithstanding, the quasimaximum likelihood estimates of $\gamma_{2}$ and $\gamma_{3}$ remain statistically different from zero and positive, so 
that the floor cool-off effect and the ceiling magnet effect persist.

Third, we redo our econometric analysis for the series of IBOVESPA futures returns at the 10 and 30 minutes frequencies. The parameter estimates have the same signs and very similar magnitudes. The only difference is that the autoregressive component becomes significant at the 10 minutes frequency in the conditional mean due to the relative larger number of zero-returns observations. To conserve on space, Table 6 reports only the estimates regarding the sampling interval of 10 minutes.

Fourth, we must make sure that our results are not driven by the particular measure we use to gauge the distance to the limits. We first allow the proximity-to-limit variables to affect the conditional mean and variance in a polynomial fashion. Table 7 documents however that the resulting specification is not congruent in that the residuals exhibit autocorrelation. At any rate, the overall results remains the same in that they are consistent with a strong floor cool-off effect and a ceiling magnet effect. Table 7 also shows that there are no significant changes in the estimation outcome if one measures the distance to the limits only by the difference of the actual price to the ceiling and floor prices (i.e., without standardizing by the admissible range of oscillation). Further analysis also shows that our main qualitative result, i.e., the strong cool-off effect in the conditional mean, remains valid if one considers a dummy approach to measure the distance to the limits as in Cho et al. (2003).

Fifth, as the intraday volatility is almost constant along the day (see Figure 3), it is perhaps not necessary, if not hazardous, to adjust the IBOVESPA futures returns by the time-of-day effect. We therefore re-estimate the $\mathrm{AR}(1)-\mathrm{EGARCH}(1,1)$ model for all the above sample periods, migration dates, sampling intervals, and proximity-to-limit variables using the nonstandardized IBOVESPA futures returns. The fact that there are no palpable differences in the parameter estimates validates our main result once more. For space reasons, we do not report these results, though they are available under request.

Finally, it is also paramount to test whether the price limit effects are an artifact due to some nonlinear serial dependence in the IBOVESPA futures returns. We then restrict attention to the period running from January to October 1997 for which there are no price limits. We estimate a pure $\operatorname{AR}(1)$-EGARCH(1,1) model and then check for residual nonlinearity using Luukkonen, 
Saikkonen and Teräsvirta's (1988) test against smooth transition autoregressive (STAR) models. The motivation relies on the fact that, as the STAR models are the parametric counterpart of neural networks (see Medeiros, Teräsvirta and Rech, 2006), such a test entails nontrivial power against a wide array of alternatives (see Lee, White and Granger, 1992). The fact that we find no evidence of neglected nonlinearity at the $1 \%$ level is a first indication that the price limit effect is genuine. Moreover, estimating the model in (1) and (2) for the period ranging from January to October 1997 with an artificial (nonexisting) daily price limit of $10 \%$ yields no evidence of neglected nonlinearity in the conditional mean. ${ }^{4}$ In particular, we find no daily price effect in the conditional mean, though some evidence of a significant ceiling magnet effect in the conditional variance, which may reflect some level effect in the volatility (see Poon and Granger, 2003).

To sum up, our results provide sound statistical evidence that the IBOVESPA futures returns are under the influence of a floor cool-off effect through the conditional mean and, possibly, a ceiling magnet effect through the volatility. Yet, it rests to resolve whether these effects of the daily price limits are also relevant in economic terms. This is the goal of the exercise we report in the next section.

\section{Is the floor cool-off effect economically significant?}

In this section, we build a trading strategy that exploits the cool-off effect of the lower limit in the dynamics of the IBOVESPA futures returns. We do not take benefit from the magnet effect that magnifies the volatility as the price approaches the ceiling for two reasons. First, a natural means to benefit from such a magnet effect is to trade the IBOVESPA futures volatility by combining put and call options on IBOVESPA futures. Unfortunately, it is impossible to conduct such an exercise for there are no available data on IBOVESPA futures options. Second, the robust analysis in the last section casts some doubt on whether the magnet effect in the conditional variance is really genuine.

Before describing our trading strategy, it is important to stress that our intention is not to evaluate whether such a strategy would beat the market, but only to establish its economic relevance. We thus focus on how it performs relative to the usual buy-and-hold benchmark. One may argue

\footnotetext{
4 To save on space, we do not report this set of results, though they are of course available upon request.
} 
that the comparison is not really fair given that we do not account for transaction costs and our strategy requires day trading. However, transaction costs at BM\&F are quite small, especially for day traders. Moreover, day trading avoids many other costs, such as permanence fees and taxes on financial profits and operations.

To take advantage of the floor cool-off effect, we build a trading strategy that depends on a intraday time series of threshold prices that equate the expected return to zero at every time $t$ as a function of the maximum daily oscillation, of the current price, and of the parameter estimates. As long as the futures and threshold prices are such that the former exceeds the latter, the day trader submits no order. However, as soon as they become such that the latter exceeds the former, the investor takes a long position on the IBOVESPA futures contracts. The trader then zeroes out the position either in the the end of the trading day or if the price mounts back exceeding the current threshold.

For the sake of comparison, we use two alternative benchmarks. The first refers to buying and holding IBOVESPA spot contracts, whereas the second relates to buying and holding IBOVESPA futures contracts. Table 8 reports their performance in terms of the annualized cumulative logreturns and Sharpe ratios. We compute their Sharpe ratio using the Brazilian Interbank Deposit Certificate (CDI) as a proxy to the annual risk-free rate given that it moves very close to the interest rates payed by the Brazilian bonds. The annualized IBOVESPA cumulative log-return of the buy-and-hold strategy is about $19.20 \%$ with a sample standard deviation of $53.23 \%$. As for the IBOVESPA futures contract, the annualized cumulative log-return amounts only to $17.80 \%$, though it has a slightly superior sample standard deviation. As the annualized cumulative return of the CDI is around 25.01\%, the Sharpe ratios of the buy-and-hold benchmarks are negative. This is in line with Bonomo and Domingues (2002), who find evidence of an inverted equity premium puzzle in the Brazilian stock market.

Table 8 also displays the in-sample performance of our trading strategy, that is to say, if one plugs in the parameter estimates from the whole sample. Our trading strategy then entails a way superior annualized return, viz. $48.85 \%$, as well as a smaller sample standard deviation. The resulting Sharpe ratio amounts to 0.549 - well above the Sharpe ratios of the two buy-and-hold benchmarks. Given that day trading on BM\&F involves no financial taxes and low transaction fees, 
it is very unlikely that accounting for such costs would substantially alter the relative performance of our trading strategy within the sample.

A last concern refers to the parameter estimates we use to compute the threshold price in our trading strategy. Given that it is unfair to plug in the estimates from the whole sample, we redo the performance analysis using the parameter estimates stemming from the two alternative subsamples in Table 4. Figure 4 portrays the performances of the different strategies. The cumulative log-returns of the buy-and-hold benchmarks are almost indistinguishable, lying below the CDI (straight) line. In contrast, varying the parameter estimates have a great influence on the annualized cumulative log-returns of our day trading strategy. As one decreases the time span of the estimation sample, the performance monotonically worsens off. Notwithstanding, the Sharpe ratio remains positive in all instances. This reinforces the relevance of the cool-off effect by revealing that it also has economic significance.

\section{Conclusion}

The financial economics literature includes arguments both in favor and against price limits. The empirical evidence is also not definitive in that there are evidence supporting both the beneficial and adverse effects of the price limits. The main dispute relates to whether the price limits have a cool-off effect that stabilizes prices once they approach a limit, or a magnet effect that accelerates prices toward the limits. We contribute to this literature by investigating transactions data from every IBOVESPA futures contract traded on the Brazilian Mercantile and Futures Exchange from January 1997 to December 1999. Although the sample covers a quite stormy period for the Brazilian financial markets, there are very few observations at the limits. This is convenient for it avoids the censoring issues that arise due to the limit hits.

We fit an AR(1)-EGARCH(1,1) model for the 20-minutes IBOVESPA futures log-returns. The estimation results indicate that the conditional mean increases as the price comes closer to the floor, whereas there is a ceiling magnet effect in the conditional variance. Inspection of the parameter estimates reveals that the floor cool-off effect in the conditional mean is much stronger than the ceiling magnet effect in the conditional variance. Altogether, our results are consistent with Arak and Cook's (1997) findings that the price limits cool-off the Treasury bill futures markets and 
with Berkman and Steenbeek's (1998) lack of evidence supporting the magnet effect in the Nikkei futures markets. Also, the ceiling magnet effect in the volatility partially accords with Subrahmanyam's (1994) conclusion that the volatility increases once prices approach the limits. Finally, we complement our statistical analysis by examining the economic relevance of the floor cool-off effect.

As for policy implications, our results suggest no reason to modify the price limit rules at BM\&F. As the floor cool-off effect impedes very large downward movements (possibly due to overreaction), it dampens the impact of financial crises. One may also extrapolate our results and argue that the ceiling magnet effect may avoid the formation of speculative bubbles. Once the bubble formation halts due to the ceiling hit, investors may reassess the fundamental value of the BOVESPA futures and spot indexes.

\section{References}

Arak, M., Cook, R., 1997, Do daily price limits act as magnets? The case of treasury bond future, Journal of Financial Services Research 12, 5-20.

Bekaert, G., Gray, S. F., 1998, Target zones and exchange rates: An empirical investigation, Journal of International Economics 45, 1-35.

Berkman, H., Steenbeek, O. W., 1998, The influence of daily price limits on trading in Nikkei futures, Journal of Futures Markets 18, 265-279.

Bonomo, M. A. C., Domingues, G. B., 2002, Os puzzles invertidos no mercado brasileiro de ativos, in: M. A. C. Bonomo (ed.), Finanças Aplicadas ao Brasil, Fundação Getulio Vargas, Rio de Janeiro.

Brennan, M. J., 1986, A theory of price limits in futures markets, Journal of Financial Economics $16,213-233$.

Cho, D. D., Russell, J., Tiao, G., Tsay, R., 2003, The magnet effect of price limits: Evidence from high-frequency data on Taiwan Stock Exchange, Journal of Empirical Finance 10, 133-168.

Chowdry, B., Nanda, V., 1998, Leverage and market stability: The role of margin rules and price limits, Journal of Business 71, 179-210.

Dhrymes, P. J., 1986, Limited Dependent Variables, in: Z. Griliches M. D. Intriligator (eds), Handbook of Econometrics, Vol. 3, North-Holland, Amsterdam, chapter 27, pp. 1567-1631.

Engle, R. F., Gau, Y.-F., 1997, Conditional volatility of exchange rates under a target zone, Discussion paper 97-06, UCSD. 
Fama, E. F., 1989, Perspectives on October 1987, or What did we learn from the crash?, in: R. W. Kamphuis Jr. R. C. Kormendi J. W. Henry Watson (eds), Black Monday and the future of the financial markets, Irwin Homewood, Illinois.

Grammig, J., Wellner, M., 2002, Modeling the interdependence of volatility and inter-transaction duration processes, Journal of Econometrics 106, 369-400.

Iannizzotto, M., Taylor, M. P., 1999, The target zone model, non-linearity and mean reversion: Is the honeymoon really over?, Economic Journal 109, C96-C110.

Kim, K. A., Rhee, S. G., 1997, Price limit performance: Evidence from the Tokyo Stock Exchange, Journal of Finance 52, 885-901.

Kim, Y. H., Yang, J. J., 2003, Price limits and overreaction, University of Cincinnati.

Kodres, L. E., O'Brien, D. P., 1994, The existence of Pareto-superior price limits, American Economic Review 84, 919-932.

Krugman, P. R., 1991, Target zones and exchange rate dynamics, Quarterly Journal of Economics $106,669-682$.

Lee, T.-H., White, H., Granger, C. W. J., 1992, Testing for neglected nonlinearity in time-series models: A comparison of neural network methods and standard tests, Journal of Econometrics $56,269-290$.

Lehmann, B. N., 1989, Commentary: Volatility, price resolution, and the effectiveness of price limits, Journal of Financial Services Research 3, 165-199.

Lo, A. W., MacKinlay, A. C., 1990, An econometric analysis of nonsynchronous trading, Journal of Econometrics 45, 181-212.

Luukkonen, R., Saikkonen, P., Teräsvirta, T., 1988, Testing linearity against smooth transition autoregressive models, Biometrika 75, 491-499.

Martens, M., 2002, Measuring and forecasting S\&P500 index-futures volatility using high-frequency data, Journal of Futures Markets 22, 497-518.

Martens, M., Zein, J., 2004, High-frequency time-series forecasts vis-à-vis implied volatility, Journal of Futures Markets. Forthcoming.

Medeiros, M. C., Teräsvirta, T., Rech, G., 2006, Building neural network models for time series: A statistical approach, forthcoming in the Journal of Forecasting.

Poon, S.-H., Granger, C. W. J., 2003, Forecasting volatility in financial markets: A review, Journal of Economic Literature 41, 478-539.

Subrahmanyam, A., 1994, Circuit breakers and market volatility: A theoretical perspective, Journal of Finance 49, 527-543. 
Wooldridge, J. M., 1991, On the application of robust, regression-based diagnostics to models of conditional means and conditional variances, Journal of Econometrics 47, 5-46. 
Table 1

The daily maximum oscillation for the IBOVESPA futures contracts

We collect the changes in the daily maximum oscillation for the IBOVESPA futures contracts traded on the Brazilian Mercantile and Futures Exchange (BM\&F) from January 1997 to December 1999. The daily price limits are set relative to the previous day's settlement price. There are no price limits prior to October 30, 1997. As well, $\mathrm{BM} \& \mathrm{~F}$ registers no alteration in the price limit rules for the IBOVESPA futures contracts since August 17, 1999.

\begin{tabular}{lr}
\hline date & daily maximum oscillation \\
\hline October 30,1997 & $10 \%$ \\
November 04,1997 & $15 \%$ \\
January 18,1999 & $25 \%$ \\
January 19,1999 & $15 \%$ \\
August 17,1999 & $10 \%$ \\
\hline
\end{tabular}




\section{Table 2}

\section{Frequency of ceiling and floor hits}

We compute the number of observations at the ceiling and at the floor from the transaction data on all IBOVESPA futures contracts traded on BM\&F from January 1997 to December 1999. We recover the daily price limits from the daily maximum oscillation by means of the series of daily settlement prices provided by BM\&F. Recall that there are no price limits before October 30, 1997. Panel A reports the numbers of ceiling and floor hits as retrieved from the daily data, whereas Panel B examines the intraday data.

\begin{tabular}{|c|c|c|c|c|}
\hline & & 1997 & 1998 & 1999 \\
\hline \multicolumn{5}{|l|}{$\underline{\text { Panel A }}$} \\
\hline & number of days & 249 & 246 & 246 \\
\hline & number of ceiling hits & 0 & 5 & 0 \\
\hline & number of floor hits & 0 & 1 & 2 \\
\hline \multicolumn{5}{|l|}{$\underline{\text { Panel B }}$} \\
\hline & number of intraday observations & 901,611 & 821,476 & 589,171 \\
\hline & number of ceiling hits & 0 & 17 & 0 \\
\hline & number of floor hits & 0 & 1 & 4 \\
\hline
\end{tabular}


Table 3

Descriptive statistics for the series of IBOVESPA futures returns

The sample runs from January 1997 to December 1999. We form a single time series for the IBOVESPA futures price by tracking the contract with the nearest expiration date and then switching to the next-maturing contract one day before the expiration of the former. We next compute continuously compounded returns at the 10 and 20 minutes frequencies and then standardize them by the sample standard deviation of their intraday time interval. Finally, we exclude all overnight returns as well as returns at the price limits.

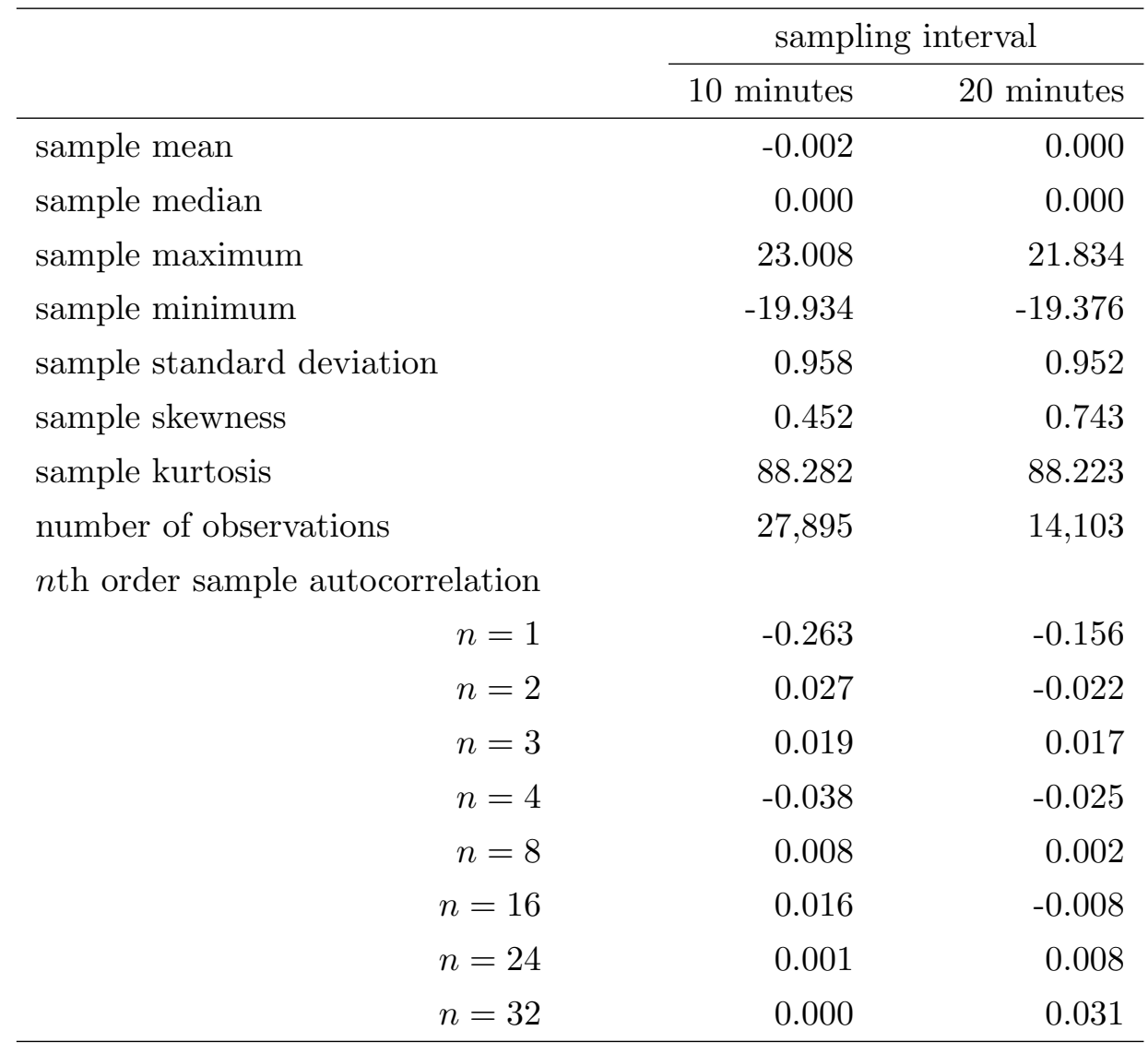




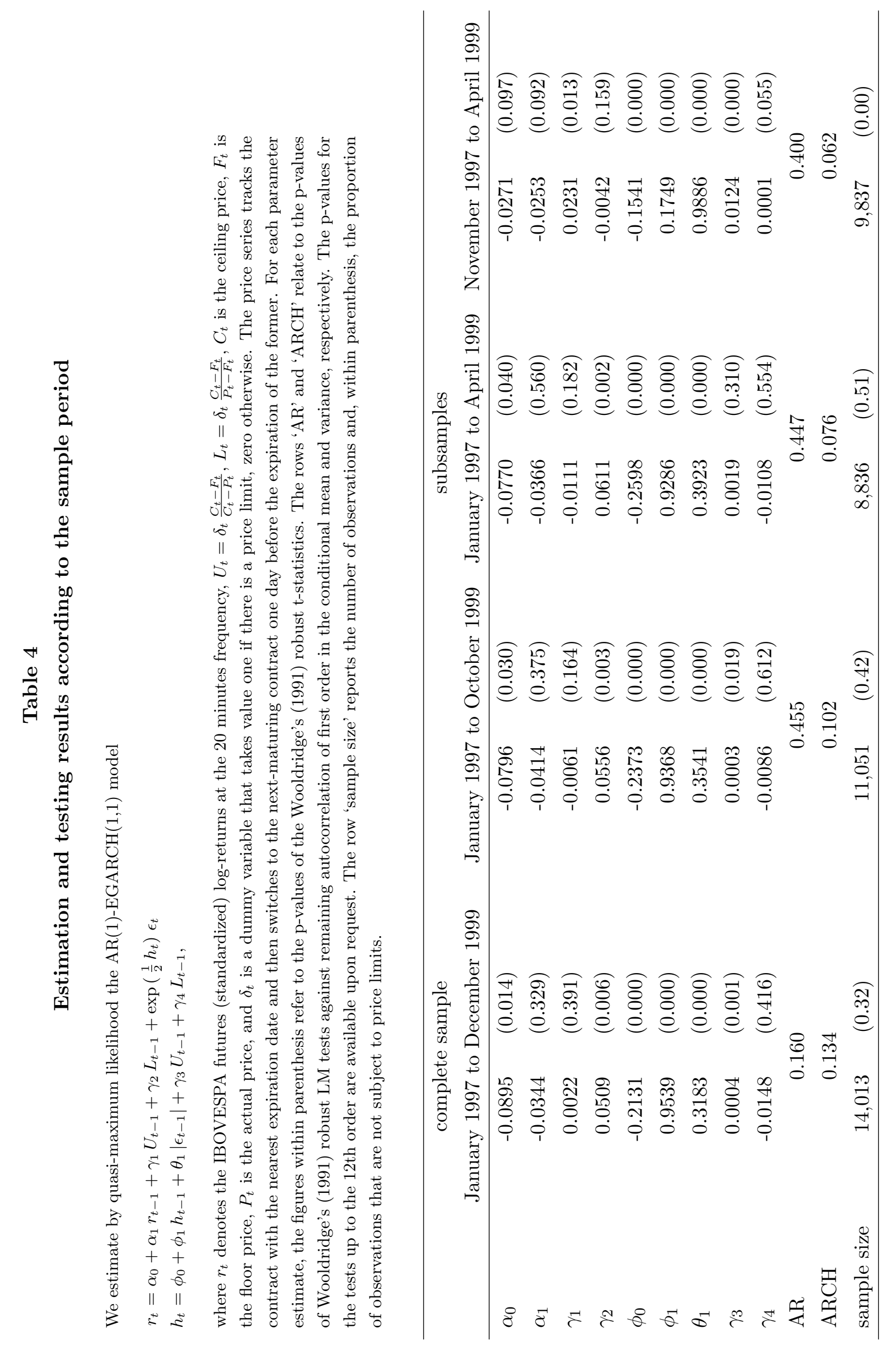




\section{Table 5}

\section{Estimation and testing results according to the migration date}

We estimate by quasi-maximum likelihood the $\mathrm{AR}(1)$-EGARCH(1,1) model

$r_{t}=\alpha_{0}+\alpha_{1} r_{t-1}+\gamma_{1} U_{t-1}+\gamma_{2} L_{t-1}+\exp \left(\frac{1}{2} h_{t}\right) \epsilon_{t}$

$h_{t}=\phi_{0}+\phi_{1} h_{t-1}+\theta_{1}\left|\epsilon_{t-1}\right|+\gamma_{3} U_{t-1}+\gamma_{4} L_{t-1}$,

where $r_{t}$ denotes the IBOVESPA futures (standardized) log-returns at the 20 minutes frequency. The proximity-to-limit variables are $U_{t}=\delta_{t} \frac{C_{t}-F_{t}}{C_{t}-P_{t}}$ and $L_{t}=\delta_{t} \frac{C_{t}-F_{t}}{P_{t}-F_{t}}$, where $C_{t}$ is the ceiling price, $F_{t}$ is the floor price, $P_{t}$ is the actual price, and $\delta_{t}$ is a dummy variable that takes value one if there is a price limit, zero otherwise. The sample runs from January 1997 to December 1999. The price series tracks the contract with the nearest expiration date and then switches to the next-maturing contract $m$ days before the expiration of the former. For each parameter estimate, the figures within parenthesis refer to the p-values of the Wooldridge's (1991) robust t-statistics. The rows 'AR' and 'ARCH' relate to the p-values of Wooldridge's (1991) robust LM tests against remaining autocorrelation of first order in the conditional mean and variance, respectively. The p-values for the tests up to the 12 th order are available upon request.

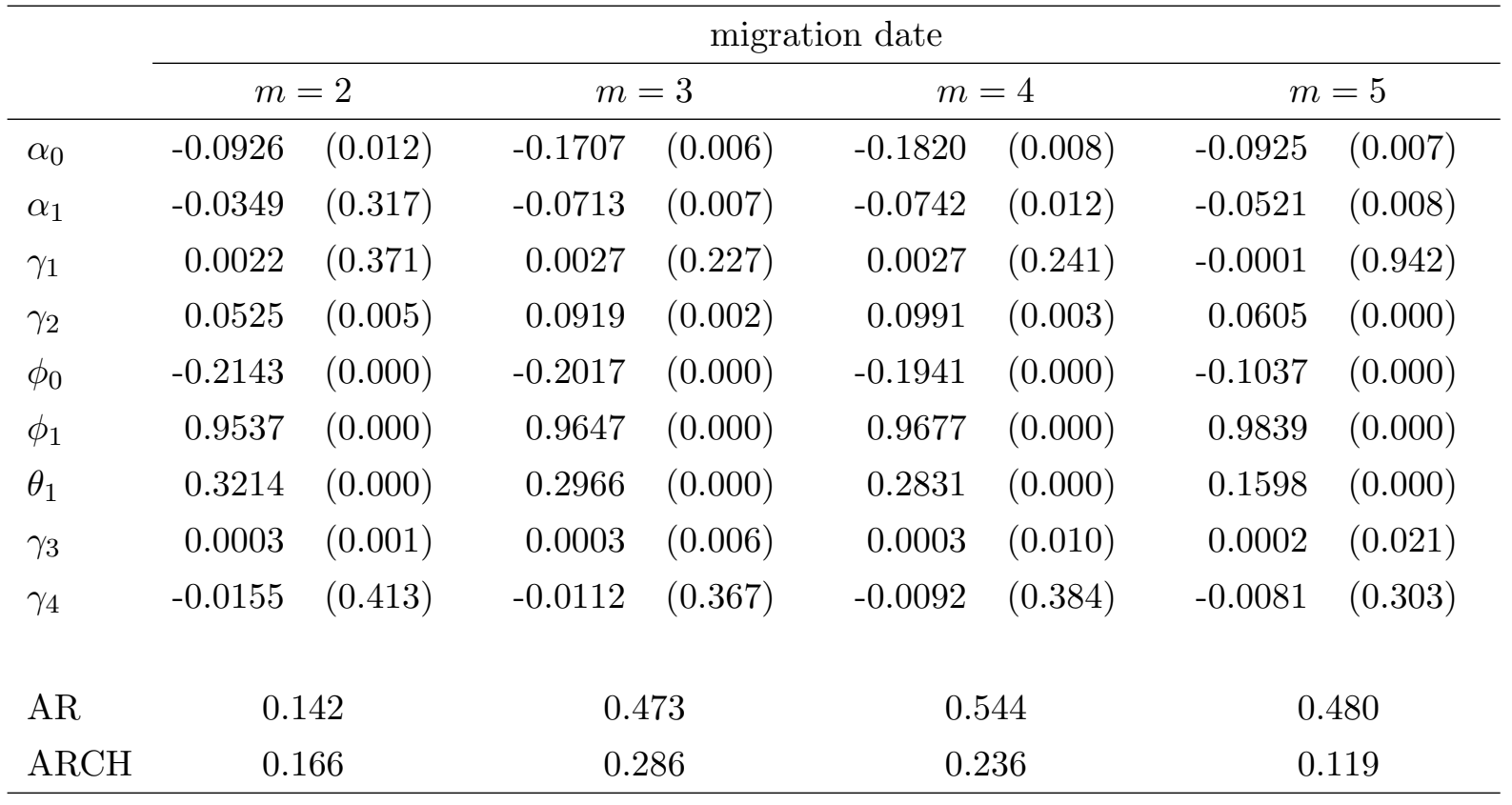




\section{Table 6}

\section{Estimation and testing results at the 10 minutes frequency}

We estimate by quasi-maximum likelihood the $\operatorname{AR}(1)-\operatorname{EGARCH}(1,1)$ model

$r_{t}=\alpha_{0}+\alpha_{1} r_{t-1}+\gamma_{1} U_{t-1}+\gamma_{2} L_{t-1}+\exp \left(\frac{1}{2} h_{t}\right) \epsilon_{t}$

$h_{t}=\phi_{0}+\phi_{1} h_{t-1}+\theta_{1}\left|\epsilon_{t-1}\right|+\gamma_{3} U_{t-1}+\gamma_{4} L_{t-1}$,

where $r_{t}$ denotes the IBOVESPA futures (standardized) log-returns at the 10 minutes frequency The proximity-to-limit variables are $U_{t}=\delta_{t} \frac{C_{t}-F_{t}}{C_{t}-P_{t}}$ and $L_{t}=\delta_{t} \frac{C_{t}-F_{t}}{P_{t}-F_{t}}$, where $C_{t}$ is the ceiling price, $F_{t}$ is the floor price, $P_{t}$ is the actual price, and $\delta_{t}$ is a dummy variable that takes value one if there is a price limit, zero otherwise. The price series tracks the contract with the nearest expiration date and then switches to the next-maturing contract one day before the expiration of the former. The sample runs from January 1997 to December 1999, including 27,895 observations. For each parameter estimate, the figures within parenthesis refer to the p-values of the Wooldridge's (1991) robust t-statistics. The rows 'AR' and 'ARCH' relate to the p-values of Wooldridge's (1991) robust LM tests against remaining autocorrelation of first order in the conditional mean and variance, respectively. The p-values for the tests up to the 12 th order are available upon request.

\begin{tabular}{|c|c|c|c|c|c|c|c|c|}
\hline \multicolumn{4}{|c|}{ conditional mean } & \multicolumn{5}{|c|}{ conditional variance } \\
\hline$\alpha_{0}$ & $\alpha_{1}$ & $\gamma_{1}$ & $\gamma_{2}$ & $\phi_{0}$ & $\phi_{1}$ & $\theta_{1}$ & $\gamma_{3}$ & $\gamma_{4}$ \\
\hline-0.043 & -0.172 & -0.004 & 0.031 & -0.179 & 0.975 & 0.273 & 0.000 & -0.008 \\
\hline$(0.111)$ & $(0.000)$ & $(0.122)$ & $(0.023)$ & $(0.000)$ & $(0.000)$ & $(0.000)$ & $(0.042)$ & $(0.261)$ \\
\hline $\mathrm{AR}$ & 0.102 & & & & & & & \\
\hline $\mathrm{ARCH}$ & 0.937 & & & & & & & \\
\hline
\end{tabular}




\section{Table 7}

\section{Estimation and testing results for the alternative proximity-to-limit variables}

We estimate by quasi-maximum likelihood $\operatorname{AR}(1)-\operatorname{EGARCH}(1,1)$ models nested by

$r_{t}=\alpha_{0}+\alpha_{1} r_{t-1}+\lambda_{1} U_{t-1}^{1 / 2}+\lambda_{2} L_{t-1}^{1 / 2}+\gamma_{1} U_{t-1}+\gamma_{2} L_{t-1}+\beta_{1} U_{t-1}^{2}+\beta_{2} L_{t-1}^{2}+\exp \left(\frac{1}{2} h_{t}\right) \epsilon_{t}$

$h_{t}=\phi_{0}+\phi_{1} h_{t-1}+\theta_{1}\left|\epsilon_{t-1}\right|+\lambda_{3} U_{t-1}^{1 / 2}+\lambda_{4} L_{t-1}^{1 / 2}+\gamma_{3} U_{t-1}+\gamma_{4} L_{t-1}+\beta_{3} U_{t-1}^{2}+\beta_{4} L_{t-1}^{2}$,

where $r_{t}$ denotes the IBOVESPA futures (standardized) log-returns at the 20 minutes frequency. The series tracks the contract with the nearest expiration date and then switches to the nextmaturing contract one day before the expiration of the former. The sample runs from January 1997 to December 1999. For each parameter estimate, the figures within parenthesis refer to the p-values of the Wooldridge's (1991) robust t-statistics. The column 'nonstandardized' considers only the terms linear on the proximity-to-limit variables as defined by $U_{t}=\frac{\delta_{t}}{C_{t}-P_{t}}$ and $L_{t}=\frac{\delta_{t}}{P_{t}-F_{t}}$, where $C_{t}$ is the ceiling price, $F_{t}$ is the floor price, $P_{t}$ is the actual price, and the dummy variable $\delta_{t}$ takes value one if there are price limits, zero otherwise. The column 'polynomial' considers the complete specification with proximity-to-limit variables $U_{t}=\delta_{t} \frac{C_{t}-F_{t}}{C_{t}-P_{t}}$ and $L_{t}=\delta_{t} \frac{C_{t}-F_{t}}{P_{t}-F_{t}}$. The rows 'AR' and 'ARCH' relate to the p-values of Wooldridge's (1991) robust LM tests against remaining autocorrelation of first order in the conditional mean and variance, respectively. The p-values for the tests up to the 12 th order are available upon request.

\begin{tabular}{lcccc}
\hline & \multicolumn{3}{c}{ alternative specifications } \\
\cline { 2 - 4 } parameters & nonstandardized & polynomial \\
\hline$\alpha_{0}$ & -0.087 & $(0.017)$ & -0.022 & $(0.215)$ \\
$\alpha_{1}$ & -0.039 & $(0.265)$ & & \\
$\lambda_{1}$ & & & 0.259 & $(0.083)$ \\
$\lambda_{2}$ & & & -0.857 & $(0.043)$ \\
$\gamma_{1}$ & 0.001 & $(0.504)$ & -0.018 & $(0.080)$ \\
$\gamma_{2}$ & 0.013 & $(0.011)$ & 0.455 & $(0.028)$ \\
$\beta_{1}$ & & & 0.000 & $(0.349)$ \\
$\beta_{2}$ & & & -0.003 & $(0.043)$ \\
$\phi_{0}$ & -0.206 & $(0.000)$ & -0.036 & $(0.050)$ \\
$\phi_{1}$ & 0.954 & $(0.000)$ & 0.967 & $(0.000)$ \\
$\theta_{1}$ & 0.312 & $(0.000)$ & 0.078 & $(0.042)$ \\
$\lambda_{3}$ & & & 0.084 & $(0.007)$ \\
$\lambda_{4}$ & & & -0.377 & $(0.000)$ \\
$\gamma_{3}$ & 0.000 & $(0.000)$ & -0.002 & $(0.046)$ \\
$\gamma_{4}$ & -0.005 & $(0.348)$ & 0.183 & $(0.000)$ \\
$\beta_{3}$ & & & 0.000 & $(0.000)$ \\
$\beta_{4}$ & & -0.002 & $(0.000)$ \\
$\mathrm{AR}$ & & & \\
$\mathrm{ARCH}$ & 0.630 & 0.000 \\
\hline & 0.130 & 0.060 \\
\hline
\end{tabular}




\section{Table 8}

\section{Performance of the trading strategies from January 1997 to December 1999}

Our trading strategy takes benefit from the floor cool-off effect in the condition mean. It depends on a time series of threshold prices that equate the expected return to zero for every $t$ as a function of the daily price limits and of the parameter estimates from the complete sample (see Table 4). It dictates that the investor must (1) buy IBOVESPA futures contracts if the price is below the threshold and (2) zero out the position either in the the end of the trading day or if the price exceeds the threshold. The benchmarks refer to buying and holding IBOVESPA spot and futures contracts. The Sharpe ratios consider the Brazilian Interbank Deposit Certificate (CDI) as a proxy to the annual risk-free rate.

\begin{tabular}{lrrr}
\hline & annualized log-return & standard deviation & Sharpe ratio \\
\hline IBOVESPA spot & 0.192 & 0.532 & -0.109 \\
IBOVESPA futures & 0.178 & 0.532 & -0.135 \\
our trading strategy & 0.485 & 0.438 & 0.549 \\
\hline
\end{tabular}




\section{Últimos Ensaios Econômicos da EPGE}

[605] João Victor Issler, Afonso Arinos de Mello Franco, e Osmani Teixeira de Carvalho Guillén. The Welfare Cost of Macroeconomic Uncertainty in the Post-War Period. Ensaios Econômicos da EPGE 605, EPGE-FGV, Dez 2005.

[606] Marcelo Côrtes Neri, Luisa Carvalhaes, e Alessandra Pieroni. Inclusão Digital e Redistribuição Privada. Ensaios Econômicos da EPGE 606, EPGE-FGV, Dez 2005.

[607] Marcelo Côrtes Neri e Rodrigo Leandro de Moura. La institucionalidad del salario mínimo en Brasil. Ensaios Econômicos da EPGE 607, EPGE-FGV, Dez 2005.

[608] Marcelo Côrtes Neri e André Luiz Medrado. Experimentando Microcrédito: Uma Análise do Impacto do CrediAMIGO sobre Acesso a Crédito. Ensaios Econômicos da EPGE 608, EPGE-FGV, Dez 2005.

[609] Samuel de Abreu Pessôa. Perspectivas de Crescimento no Longo Prazo para o Brasil: Questões em Aberto. Ensaios Econômicos da EPGE 609, EPGE-FGV, Jan 2006.

[610] Renato Galvão Flôres Junior e Masakazu Watanuki. Integration Options for Mercosul - An Investigation Using the AMIDA Model. Ensaios Econômicos da EPGE 610, EPGE-FGV, Jan 2006.

[611] Rubens Penha Cysne. Income Inequality in a Job-Search Model With Heterogeneous Discount Factors (Revised Version, Forthcoming 2006, Revista Economia). Ensaios Econômicos da EPGE 611, EPGE-FGV, Jan 2006.

[612] Rubens Penha Cysne. An Intra-Household Approach to the Welfare Costs of Inflation (Revised Version, Forthcoming 2006, Estudos Econômicos). Ensaios Econômicos da EPGE 612, EPGE-FGV, Jan 2006.

[613] Pedro Cavalcanti Gomes Ferreira e Carlos Hamilton Vasconcelos Araújo. On the Economic and Fiscal Effects of Infrastructure Investment in Brazil. Ensaios Econômicos da EPGE 613, EPGE-FGV, Mar 2006.

[614] Aloisio Pessoa de Araújo, Mario R. Páscoa, e Juan Pablo Torres-Martínez. Bubbles, Collateral and Monetary Equilibrium. Ensaios Econômicos da EPGE 614, EPGE-FGV, Abr 2006.

[615] Aloisio Pessoa de Araújo e Bruno Funchal. How much debtors' punishment?. Ensaios Econômicos da EPGE 615, EPGE-FGV, Mai 2006.

[616] Paulo Klinger Monteiro. First-Price Auction Symmetric Equilibria with a General Distribution. Ensaios Econômicos da EPGE 616, EPGE-FGV, Mai 2006. 
[617] Renato Galvão Flôres Junior e Masakazu Watanuki. Is China a Northern Partner to Mercosul?. Ensaios Econômicos da EPGE 617, EPGE-FGV, Jun 2006.

[618] Renato Galvão Flôres Junior, Maria Paula Fontoura, e Rogério Guerra Santos. Foreign direct investment spillovers in Portugal: additional lessons from a country study. Ensaios Econômicos da EPGE 618, EPGE-FGV, Jun 2006.

[619] Ricardo de Oliveira Cavalcanti e Neil Wallace. New models of old(?) payment questions. Ensaios Econômicos da EPGE 619, EPGE-FGV, Set 2006.

[620] Pedro Cavalcanti Gomes Ferreira, Samuel de Abreu Pessôa, e Fernando A. Veloso. The Evolution of TFP in Latin America. Ensaios Econômicos da EPGE 620, EPGE-FGV, Set 2006.

[621] Paulo Klinger Monteiro e Frank H. Page Jr. Resultados uniformemente seguros e equilíbrio de Nash em jogos compactos. Ensaios Econômicos da EPGE 621, EPGE-FGV, Set 2006.

[622] Renato Galvão Flôres Junior. DOIS ENSAIOS SOBRE DIVERSIDADE CULTURAL E O COMÉRCIO DE SERVIÇOS. Ensaios Econômicos da EPGE 622, EPGE-FGV, Set 2006.

[623] Paulo Klinger Monteiro, Frank H. Page Jr., e Benar Fux Svaiter. Exclusão e multidimensionalidade de tipos em leilões ótimos. Ensaios Econômicos da EPGE 623, EPGE-FGV, Set 2006.

[624] João Victor Issler, Afonso Arinos de Mello Franco, e Osmani Teixeira de Carvalho Guillén. The Welfare Cost of Macroeconomic Uncertainty in the Post-War Period. Ensaios Econômicos da EPGE 624, EPGE-FGV, Set 2006.

[625] Rodrigo Leandro de Moura e Marcelo Côrtes Neri. Impactos da Nova Lei de Pisos Salariais Estaduais. Ensaios Econômicos da EPGE 625, EPGE-FGV, Out 2006.

[626] Renato Galvão Flôres Junior. The Diversity of Diversity: further methodological considerations on the use of the concept in cultural economics. Ensaios Econômicos da EPGE 626, EPGE-FGV, Out 2006.

[627] Maurício Canêdo Pinheiro, Samuel Pessôa, e Luiz Guilherme Schymura. $O$ Brasil Precisa de Política Industrial? De que Tipo?. Ensaios Econômicos da EPGE 627, EPGE-FGV, Out 2006.

[628] Fabio Araujo, João Victor Issler, e Marcelo Fernandes. A Stochastic Discount Factor Approach to Asset Pricing Using Panel Data. Ensaios Econômicos da EPGE 628, EPGE-FGV, Nov 2006.

[629] Luiz Renato Regis de Oliveira Lima e Breno de Andrade Pinheiro Neri. Comparing Value-at-Risk Methodologies. Ensaios Econômicos da EPGE 629, EPGEFGV, Nov 2006. 